\title{
O vício inerente: Fronteiras materiais, simbólicas e morais nas apostas do turfe
}

The inherent vice: material, symbolic and moral boundaries in the bets of the turf

\section{Rômulo Bulgarelli Labronici}

\section{(2) OpenEdition}

Edição electrónica

URL: http://journals.openedition.org/aa/2813

DOI: $10.4000 /$ aa. 2813

ISSN: 2357-738X

\section{Editora}

Programa de Pós-Graduação em Antropologia Social (UnB)

Edição impressa

Data de publição: 1 julho 2018

Paginação: 67-92

ISSN: 0102-4302

\section{Refêrencia eletrónica}

Rômulo Bulgarelli Labronici, «O vício inerente: Fronteiras materiais, simbólicas e morais nas apostas do turfe», Anuário Antropológico [Online], v.43 n. 1 | 2018, posto online no dia 26 maio 2019, consultado o 28 abril 2021. URL: http://journals.openedition.org/aa/2813 ; DOI: https://doi.org/10.4000/aa.2813

\section{cc) (†)}

Anuário Antropológico is licensed under a Creative Commons Atribuição-Uso Não-Comercial-Proibição de realização de Obras Derivadas 4.0 International. 


\section{$O$ vício inerente: fronteiras materiais, simbólicas e morais nas apostas do turfe}

Rômulo Bulgarelli Labronici

UFF

\section{Introdução}

As práticas de corridas de cavalos, denominadas de turfe, foram estabelecidas no início do século XIX, sendo uma das atividades pioneiras no âmbito das competições esportivas. A prática destacava-se pela sua organização de calendários de competição, formação de clubes, pelo desenvolvimento de um corpo técnico especializado e por sua adesão popular, fato este que gerou um enorme mercado ao seu redor. Além disso, em grande medida, a popularidade desta atividade se deu pela sua extensa aproximação com os jogos de apostas, o que marcou definitivamente a existência do turfe no cenário do mercado de diversões esportivas e que permanece até a atualidade movimentando recursos e um público cativo de jogadores (cf. Carvalho, 1998a, 1998b, Melo, 2001).

Apesar da extensa popularidade das apostas no turfe, esta prática aponta para uma fronteira moral existente em seu cotidiano. Durante a realização dos jogos, um sinal de alerta é constantemente acionado aos limites da relação individual com o jogo no turfe. Assim, este trabalho busca discutir como os discursos e as representações nativas do jogo estão sempre alinhados a partir de uma "normalidade" (Foucault, 1978, 2000) que impõe limites (materiais, simbólicos e morais) constantes para que o jogo possa ser exercido em uma série continuada. Segundo Gilberto Velho (2004), ao se perceber a vida social como um processo, contraditório e complexo, em que a realidade tem de ser permanentemente negociada por diferentes atores, o conflito passa a ser encarado como um fenômeno a ser pesquisado. "Sistemas de acusação" podem, segundo ele, desempenhar funções e delimitar fronteiras com uma estratégia mais ou menos consciente de manipular poder e organizar emoções.

Creio, aqui, ser possível abrir uma ponte de comparação entre a categoria viciado [no jogo] com a de drogado - em Velho (2004) -, em que ambas se tornam acusações morais que assumem explicitamente uma dimensão política, sendo, portanto, também uma acusação totalizadora. Há a ideia de que há acu- 
sações que são parciais porque ficam no nível de segmentos ou aspectos particulares do comportamento enquanto existem outras que contaminam toda a vida dos indivíduos acusados. Em muitos casos, os limites morais empregados pelos próprios jogadores reproduzem a dualidade entre o lazer lúdico e o vício em potencial, inserindo duas faces representativas na mesma atividade. Dualidade esta que estabelece na categoria do "vício", ou de "viciado", as bases do "estigma" do jogador.

Ao reexaminar o conceito de “estigma”, Erving Goffman (1988) tem o propósito de esclarecer suas relações com a questão do desvio. Para tal, apresenta conceitos relativos à informação social: a informação que o indivíduo transmite diretamente sobre si. Segundo ele, o termo se refere a um atributo profundamente depreciativo. Entretanto, mesmo diante dessa colocação, concebe o significado da palavra para além do fator atribuído quando salienta que, para a sua compreensão, é necessária uma linguagem de relações e não de atributos, uma vez que, um atributo que estigmatiza uma pessoa pode confirmar a normalidade de outra.

Desta forma, esse trabalho se baseou em uma longa pesquisa etnográfica com apostadores do turfe no âmbito do mercado de jogos nas ruas da cidade do Rio de Janeiro e busca esclarecer a construção da categoria de "vício" dentro e fora dos espaços de jogo. Para isso, estabeleceu uma linha comparativa entre as reuniões de grupos de jogadores do turfe com as reuniões dos grupos de autoajuda, ou ajuda mútua, denominados de Jogadores Anônimos (J.A.).

A abordagem metodológica se estruturou nos moldes da tradicional "observação participante” com apostadores e se deu de modo a, não apenas estar presente nas reuniões, mas participar dos mais variados tipos de apostas realizados no estabelecimento. Por outro lado, houve um concomitante acompanhamento das reuniões do J.A. que são abertas ao público. Haja vista que ocorrem algumas reuniões que são exclusivas para membros "anônimos". Por razões óbvias, as práticas dos frequentadores do J.A. não são as mesmas que as realizadas nas casas de jogo devido ao foco na abstinência. Apesar disso, a participação se deu de modo a entender como o jogo, mesmo que não sendo praticado, se constitui como o foco nas reuniões do J.A.

Esta multiplicidade de espaços, supostamente antagônicos, é aqui aproximada através da elaboração da categoria "vicio", ou "viciado", que é formulada de maneira distinta, porém complementar, entre esses grupos. Assim, a estratégia de comparar estes espaços foi antes uma busca por compreender 
as potencialidades e os limites da categoria "vício" e das distintas moralidades que circunscrevem as apostas do que uma tentativa de produzir uma "etnografia multi-situada" (Marcus, 1995). Devido a esta característica da análise em questão, e, em busca de uma organização textual, o trabalho foi dividido em três partes: a primeira, uma apresentação etnográfica das reuniões do turfe e o cotidiano de seus frequentadores com as apostas. A segunda apresenta uma discussão com a categoria de "vício" e a sua formulação neste espaço e, por fim, a última parte se apresenta como um contraponto com as reuniões de jogadores anônimos de modo a comparar as distintas percepções morais dos jogos de apostas. A perspectiva comparada entre estes dois espaços possui o intuito de explicitar distintos dispositivos acionados pelos atores, apresentando a moralidade como um “campo de disputas” (Bourdieu, 2004) na prática de jogos de apostas. Pensar a partir do conceito de campo é pensar de forma relacional. É conceber o objeto ou fenômeno em constante relação e movimento.

O campo também pressupõe confronto, tomada de posição, luta, tensão, poder, já que, de acordo com Bourdieu, todo campo "é um campo de forças e um campo de lutas para conservar ou transformar esse campo de forças" (Bourdieu, 2004:22-23). São formados por agentes, que podem ser indivíduos ou instituições, os quais criam os espaços e os fazem existir pelas relações que aí estabelecem. Um dos princípios dos campos, à medida que determina o que os agentes podem ou não fazer, é a "estrutura das relações objetivas entre os diferentes agentes” (Bourdieu, 2004:23). Assim, é o lugar que os agentes ocupam nessa estrutura que indica suas tomadas de posição.

No turfe, afirma-se que se joga com conhecimento, com sabedoria e com a sorte. Uma aposta não é somente um mero ato de jogar dinheiro, mas está partilhada dentro de um conjunto de códigos, etiquetas e moralidades em um universo de significados dotados de sentidos particulares. Para se tornar um jogador de turfe, não basta realizar uma única aposta, pois para isso é necessário o estabelecimento de uma série continuada de jogos e que tende a se autorreproduzir. Sob uma perspectiva marginal, os limites morais aqui discutidos estão inseridos na lógica fronteiriça do limite/limiar (Deleuze, 2008:130-2) que estabelece o jogo limite como a penúltima jogada, pois possibilita que sua continuidade se estabeleça para competições futuras. 


\section{As reuniões do turfe}

Como mencionado, nas carreiras do turfe, uma questão evidencia dois lados distintos e paradoxalmente complementares, sendo por muitos considerada uma atividade de prazeres a partir de uma diversão inocente, oriundas do universo lúdico, e, ao mesmo tempo, como uma atividade embebida de perigos e vícios. Ao longo do extenso trabalho de campo com o turfe, questionamentos foram levantados por interlocutores em ambos os sentidos: como uma prática meramente inofensiva ou como uma atividade potencialmente perigosa.

Devo destacar, inicialmente, que as casas de aposta do Jockey Club Brasileiro denominadas de Agências Credenciadas ${ }^{1}$ se transformaram em espaços privilegiados para o estudo de jogos no meio urbano, pois concentram, em um determinado espaço da cidade, jogadores e apostadores, habituais e esporádicos de maneira sistemática e rotineira. Tais agrupamentos de aficionados que permanecem em volta desses estabelecimentos de jogo são denominados de "reuniões do turfe". As reuniões são importantes eventos para contato pessoal entre os coparticipantes. O termo "reunião", no turfe, é inicialmente atrelado ao conjunto de corridas que ocorrerão em um dia, em um ou mais hipódromos, e que poderão ser transmitidas e televisionadas nas casas de apostas. Entretanto, no contexto das casas de jogo, as reuniões podem também ser entendidas a partir do ponto de vista dos jogadores.

Uma reunião do turfe é, consequentemente, uma reunião de jogadores dispostos a sociabilizar mediante a prática de apostas. Georg Simmel define a noção de sociabilidade como "a forma lúdica da sociação" (Simmel, [1908] 1983:168). Concebendo a sociedade como produto das interações individuais, Simmel formula o conceito de sociação para designar mais apropriadamente as formas ou modos pelos quais os atores sociais se relacionam. Por outro lado, a sociabilidade é uma forma de interação na qual os participantes se mostram, a um só tempo, interessados e descomprometidos, autonomizando suas atuações no sentido de evitar qualquer demonstração num interesse objetivo nos assuntos tratados. A partir deste conceito, é possível enquadrar os tipos de interações que se estabelecem nas reuniões do turfe.

Dentre as formas de sociação estudadas por Simmel, destaco o conflito, situação em que as relações dos indivíduos são compreendidas como relações de cooperação, mas também de oposição; portanto, ambas são partes da constituição do grupo, um elemento constituinte das relações sociais com a capacidade de 
produzir e modificar grupos de interesse, uniões e organizações. Deste modo, tais reuniões ocorrem ao longo de vários dias e possuem um número variado de apostadores com um grau de liberdade que permite uma maior fluidez no conjunto agrupado, pois jogadores podem permanecer o dia todo jogando, ou apenas algumas poucas horas.

Esses espaços utilizados para o jogo se tornam arenas de sociabilidade de jogadores onde constantes incentivos ao jogo são realizados de modo a partilhar as experiências das corridas. Sistematicamente, é possível escutar indagações, convites e provocações para apostar: "Você não joga hoje, não?", "Você já viu como é gostosinho brincar disso aqui, se quiser eu te ajudo a montar uma boa hoje", "No sete [páreo] tenho uma "barbada" ${ }^{2}$ boa pra te arrumar.", "Ih deixa o cara que hoje ele vai guardar o dinheiro pro Toddynho ${ }^{3}$, já cansou de jogar dinheiro fora." Provocações, questionamentos, instigações e chamamentos ao jogo são corriqueiros no sentido de (re)inserir uns aos outros no universo das apostas, dando continuidade a experiência turfística. Até mesmo no âmbito da pesquisa, jogadores teciam comentários que, em sua maioria, traziam o entendimento de que para compreender o turfe era necessário jogar. Pois, segundo a lógica turfísta, estar presente em espaços de jogo e não apostar, ou não possuir o hábito de jogo, se tornara algo vazio de sentido. Jogadores assim pareciam se tornar mais confortáveis ao fato de que mesmo um "não jogador" ali presente pudesse também tentar acertar o vencedor do páreo e, com isso, compartilhar as experiências com os demais.

Por outro lado, em outros momentos, o fato de uma pessoa não habitual realizar uma aposta se tornava algo questionável. Indivíduos esporádicos e pontuais acionam um sinal de alerta com relação à cautela dos "limites" da relação com o jogo no turfe. A gerente Sandra é uma que sempre tecia comentários do tipo: "Você 'tá jogando?! Cuidado, heim! Olha como são esses velhos aí. Pode até passar uma mulher bonitona na frente deles que eles não vão nem perceber, só pensam nos cavalos".

Com um tom extremamente reprovativo, Sandra insistentemente questionava o papel dos jogadores, afirmando que esta atividade teria um potencial para "estragar a vida". O mesmo ocorria com outra interlocutora que chegou a tentar impedir que apostadores jogassem, afirmando que: "Meu objetivo aqui é salvar vidas. Não podem jogar a vida fora dessa maneira!". Com isso, ela afirmava que não se deveria mexer com esta atividade devido ao seu potencial devastador. Do 
mesmo modo, o jogador Paulinho, ao me ver realizando uma aposta, comentou: "Ih garotinho, tá apostando? Daqui a pouco tu vai ficar igual a esses caras!". O comentário de Paulinho referia-se ao suposto comportamento reprovável de seus colegas e amigos de turfe, apesar dele próprio estar inserido diariamente nas casas de jogo, apostando em uma grande quantidade de páreos por dia. As falas destes interlocutores deixam explícito que até mesmo espaços destinados ao jogo de apostas são capazes de acionar alertas em relação às práticas desta atividade.

A partir desse duplo viés que a atividade de apostas apresenta, é possível discutir os limites morais empregados pelos próprios jogadores na questão da dualidade entre o lazer lúdico e a atividade viciante. São duas faces representativas de uma mesma atividade. Uma que estabelece o vício, ou o viciado ${ }^{4}$, como um perigo em potencial e a outra como uma atividade que possui um status essencialmente lúdico. Duas representações supostamente opostas, mas que, segundo os discursos de meus interlocutores, se estabelecem em uma relação de complementaridade.

Inicialmente, é possível afirmar que nas casas de apostas a categoria "viciado" se apresenta como uma "categoria de acusação" (Velho, 2004) para os jogadores que, de certa forma, não são capazes de compreender e jogar como idealmente deveria ser. Enquanto que, por outro lado, a atividade era apresentada como detentora de um sinal de perigo, potencialmente danoso e socialmente desestruturante para os que se aventuram buscar a sorte com os cavalos. Uma prática que levaria a uma possível perda de autocontrole da própria agência do jogador, sendo prejudicial para si próprio e para os demais a sua volta. Segundo Mary Douglas: "Cremos que as crenças de poluição reforçam-no de duas diferentes maneiras: ou o próprio transgressor é considerado vítima de seu próprio ato ou alguma vítima inocente sofre o ataque do perigo" (Douglas, [1966] 2010:164). Assim, a construção do "estigma” do jogador, aos que não partilham do universo turfístico, apresenta todo jogo como uma atividade potencialmente perigosa em que o estigma faz alusão à situação do indivíduo que está inabilitado para a aceitação social plena (Goffman, 1988). Entretanto, dentro dos espaços de jogo, o perigo não mais é apresentado como um todo, mas como uma fuga a uma postura normativa de jogador. Deste modo, a experiência adquirida em campo esteve sempre muito marcada por esses dois aspectos, onde os jogadores se encontravam estimulando uns aos outros para o jogo, porém com limites muito particulares nos quais os possíveis perigos do jogo passam, inicialmente, pela chave de uma suposta perda de autocontrole. 
Os discursos e as representações nativas do jogo estão sempre apresentados a partir de uma "normalidade" (Foucault, 1978) e na tênue linha separativa com a anormalidade, que impõe limites (materiais, simbólicos e morais) ao jogo para que ele possa se estabelecer numa série contínua de jogos, isto é, para que um jogador possa frequentar uma casa de apostas sem que com isso ele se considere um viciado. E, dentro deste espaço, o turfe se apresenta como a atividade mais representativa, isto é, entre as distintas modalidades de aposta, as do turfe são as consideradas com o maior potencial destrutivo. Como afirmou Carlos, um dos jogadores do clube de carteado estabelecido nas imediações de uma das casas de apostas do turfe da cidade:

Eu tenho o espírito de jogador, gosto muito disso [apostas em geral]. Não posso aprender a jogar isso aqui [turfe] não, se não, eu me lasco. Sou um jogador inveterado e não consigo me controlar. Tenho que ficar nas cartas mesmo. Eu convivo e sou amigo de muitos desses caras [jogadores do turfe], mas não me atrevo a aprender não.

O estigma (Goffman,1988) associado aos apostadores de cavalo, devido a facilidade na perda do autocontrole e dos gastos elevados das apostas, faz das apostas no turfe um tipo de consumo de jogo visceral no qual a diversão e o seu lado lúdico são, muitas vezes, deixados de fora da equação. O Historiador John Burnham (1993), ao lidar com hábitos estigmatizados e maculados por uma potencialidade socialmente desestruturante como são representadas as apostas turfe, afirma: "Como o uso de drogas, o jogo minou a ética do trabalho e encarna o perigo do vício” (Burnham, 1993:146). O vício dos jogos de apostas é algo que mostra que, apesar de ser um simples jogo, ele ainda possui um status transgressor, e o autor continua:

Estava implícito que o hábito de apostas, associado a fraudes e trapaças, era a consequência prática de que o jogo vitimava pessoas, seja em apostas informais com estranhos não confiáveis ou na publicidade enganosa que incentivava os crédulos à comprar bilhetes de loteria. (...) As pessoas nunca duvidaram que o jogo foi invariavelmente associado com os outros vícios menores e, particularmente, com o consumo de álcool. O estereótipo de vida fácil já estava bem estabelecido, ligando o jogo com o fumo, a bebida e a desordem. (Burnham, 1993:147-150). 
A antropóloga Rebecca Cassidy (2002) também demonstra como a questão dos jogos em corridas de cavalos possui um vínculo moral condenável em seu país de origem:

Em 1853 a Lei de apostas [Gambling Law] "fez pouca diferença para as apostas em si”, que floresceu na economia informal, a era do street-bookie nas ruas. Um ressurgimento da condenação moral do jogo foi identificado como a causa do alcoolismo, a pobreza e regressão moral (Cassidy, 2002:71).

Até mesmo para jogadores experientes, as corridas de cavalo continuam associadas a um tipo de atividade inserida num universo de "malandros" (Damatta, 1979) e "vagabundos" (Misse, 1999). Em conversa com o jogador Carlos, ele afirma:

Jogador de corrida de cavalos é muito estigmatizado. Se não tem um dinheiro pra pagar uma conta, é porque perdeu nas corridas. Se não pode comprar um remédio, é culpa das corridas. Se perdeu a carteira, gastou nas corridas. Tudo de errado que acontece na nossa vida é por causa do jogo.

Como afirma o jogador Carlos, um dos pontos centrais do estigma do jogador de corridas de cavalos insere-se na chave da perda (semi ou total) de bens. O antropólogo norte-americano Clifford Geertz, traz à tona o conceito de Jeremy Bentham de "jogo profundo" [Deep game], conceito que atribui significados aos jogos nos quais as apostas seriam tão altas que, do ponto de vista utilitarista, seria irracional para os homens se envolverem, chegando numa relação que traria aos participantes consideravelmente mais dor do que prazer. A conclusão de Bentham, portanto, é de que o jogo profundo é imoral a partir de seus princípios básicos e que deveria ser legalmente proscrito (cf. Bentham apud Geertz [1973] $2008: 199$ ).

Tal representação estigmatizada é ainda refletida, em menor escala, nas casas de jogos por parte dos próprios jogadores. Nas casas de apostas, o jogador Tião, que aprendeu a jogar desde criança, quando seu avô o colocava para estudar ${ }^{5}$ o programa do turfe, afirma categoricamente: "Isso é pior que heroína, pior que crack. Já vi gente virar mendigo com isso aqui. Quer saber quem é que ganha com isso tudo aqui!? É o Jockey [Clube], ninguém mais”. Apesar disso, Tião não deixa de frequentar as casas de apostas diariamente, jogando sempre 
que pode. Assim, a representação do turfe por parte de alguns jogadores seria a "pior" das atividades de jogo. Afirmações do tipo: "No [jogo do] bicho você deixa uns trocados, no cavalo você deixa a casa!”, ou “as cartas são minha diversão, o cavalo a coisa é séria”, são constantes e contribuem para reforçar a ideia de cuidados necessários quando a questão é o turfe. Tais assertivas, em geral, possuem a função comparativa e são frequentemente enunciadas, remetendo a tais "perigos" das apostas nos cavalos. Como afirma Geertz, no trabalho com as rinhas de galo em Bali existiria uma "hierarquia sócio-moral” ([1973] 2008:200), distinguindo jogos de status e jogos de "dinheiro". Entretanto, no caso do turfe, uma das fontes de status e hierarquia social entre os jogadores seriam, justamente, os valores atrelados às apostas e aos ganhos monetários.

\section{Perdas e ganhos viciantes}

Em uma conversa com os jogadores Choppinho e Ivan, ambos comentam sobre esta questão ao dar como exemplo a história do jogador Milionário, atual guardador de carros da rua em frente à casa de apostas de um bairro próximo à região central da cidade.

Choppinho: Pô, foi assim que ele ganhou o apelido. Milionário chegou a ganhar uma bolada muito forte. Se eu não me engano, chegou a quase meio milhão pra época.

Ivan: Não foi isso tudo não, Choppinho, olha o exagero! Aquilo lá não deve ter chegado nem a duzentos mil. (...) Que seja! Ele ganhou uma bolada que não se vê todo dia. Era pra ele estar melhor do que eu, modéstia à parte. Mas não, ele vinha pra cá, bancava de patrão e de que era o cara e coisa e tal. Só fazia apostas altas aqui, já gastou mais de cinco conto [cinco mil reais] numa reunião que eu lembro. E pra piorar ainda foi se meter com jogo de ronda ${ }^{6}$ e coisa e tal.Vinha aqui e gastava o que tinha e o que não tinha. Só faltou jogar dinheiro pro alto. Depois ia direto pra mesa de ronda lá em Copacabana. Se metia com banqueiro de bicho e esses caras ai. Ô, tá ai de novo, perdeu tudo. Não tem um centavo do dinheiro do prêmio."

O “controle” (Elias, 1994, 2001) se apresenta como uma mudança na conduta e sentimentos humanos em uma direção bastante específica. Apesar das transformações não seguirem uma razão intencional, elas obedecem uma ordem. Trata-se do aumento externo do controle das emoções que se converte em auto- 
controle. E no turfe ele é exercido pelos próprios jogadores e atravessa a chave dos gastos monetários e da volatilidade em seus orçamentos de jogo, principalmente quando o dinheiro ganho é menor do que dinheiro gasto.

Os mecanismos de poder sobre os indivíduos, como os diversos discursos de vários saberes, foram capazes de criar certas modalidades de subjetivação a ponto de produzir sujeitos com suas práticas e estratégias de regularização, normalização e controle. Aqui o jogador é visto, como em Foucault (2000), como elaborado, trabalhado e constituído, segundo critérios de estilo por meio de tecnologias de saber, de poder e de si, por ele consideradas de tecnologias do eu. Como o autor mostra, ao longo da sua obra, cada um de nós, enquanto sujeito, é o resultado de uma produção que se dá no interior do espaço delimitado pelos três eixos da ontologia do presente: os eixos do ser-saber, do ser-poder e do ser-si. São, portanto, os dispositivos e suas técnicas de fabricação, dentre as quais a disciplinaridade é um grande exemplo, que instituem o que chamamos de sujeito. Neste sentido, cada um faz não o que quer, mas aquilo que pode; aquilo que lhe cabe na posição de sujeito que ele ocupa numa determinada sociedade, submetido aos ditames de instituições sociais e políticas. A história de Milionário narrada pelos dois jogadores remete a esta questão, na qual o ponto central da discussão era o estabelecimento de controles financeiros aos usos e gastos com apostas. O "descontrole" (ou a falta de disciplina) de Milionário gerou uma discussão referente aos limites e controles de si, estabelecidos pelos próprios jogadores da prática do turfe.

Ao ser interpelado sobre seu grande prêmio, Milionário sempre desconversa, não relatando detalhes de como ganhou e "perdeu" seu prêmio que originou seu apelido. Apenas se resume a soltar questionamentos referentes ao caráter e à moral de seus competidores, acusando-os de trapaças e roubos que culminaram na perda de sua pequena "fortuna”. Neste caso, o erro, ou o descontrole de Milionário, segundo os olhos dos demais jogadores, não pode ser aceito por ele como um problema pessoal com o jogo. Caso contrário, esta postura poderia causar uma ruptura limiar, no sentido apresentado por Deleuze (2008), impedindo que o jogo permanecesse da mesma forma para ele. Pela manutenção e continuidade da série de seus jogos, a culpa da perda de seu prêmio é transferida a terceiros. Em seu discurso não houve por ele uma má apropriação do jogo, nem descontrole ou descuidos. Na visão dos jogadores, isso acontece com aquele que não consegue manter um controle sobre suas ações e tem na categoria do "vício" a sua motivação. 
Saber estipular os limites, na maioria das vezes subjetivos, do controle dos gastos é uma das chaves desta questão. O uso acusatório desta categoria está relacionado aos que, em alguns destes aspectos, não possui as qualidades (ou capacidades) pessoais para praticar as formas ideais de se jogar o jogo, ao mesmo tempo em que tais limites seriam imprescindíveis para a manutenção do aspecto lúdico do jogo a longo prazo.

Assim, para os jogadores, a chave do vício passa mais por uma questão de não saber jogar como se deve, indisciplinadamente (Foucault, 2000). O mesmo ocorre com aqueles que, a partir de perdas, buscam reaver apostas que já foram perdidas. O autor Sérgio Barcellos (2002) apresenta os dez mandamentos do apostador $^{7}$ e o décimo exemplifica esta questão:

(...) 10- Quanto a correr atrás dos prejuízos - e eles são inevitáveis nesta atividade - entendo que nenhum apostador pode se dar ao luxo de perder o autocontrole e a autoestima. Isso é coisa pra amadores, que se irritam e se abatem facilmente com as perdas. Ganhando ou perdendo, tente ser objetivo e adulto, e melhore seu padrão de jogo da próxima vez (Barcellos, 2002:81)

Deste modo, quanto aos gastos das apostas no turfe, os limites são sistematicamente elaborados de modo a evitar gastos elevados, pois, segundo a lógica no jogo, perder é uma situação considerada "normal”. Quanto a isso, o jogador Choppinho afirma: "Dificilmente eu gasto mais do que 70 ou 80 Reais por dia. Esse é o meu máximo [limite monetário]. Se passar disso vira putaria, não dá. Meu bolso não aguenta”. Em outras ocasiões, o mesmo jogador Choppinho chegou à casa de apostas com bolos de notas de cem reais, dobradas e cujo somatório chegava a mais de mil reais a serem gastos em um único dia de corrida. Falando para todos com um ar de orgulho nos olhos, brandia as notas para que todos pudessem ver: “Aqui, óh! Isso aqui é pra hoje!”. Embora o próprio Choppinho, assim como muitos de seus companheiros de jogo, estabeleça limites subjetivos para o seu controle orçamentário do volume de jogo, tais regras não são seguidas à risca. Em diversas ocasiões foi possível observar gastos muito superiores aos estabelecidos por ele em um único páreo do dia.

Tais limites inseridos nos gastos do jogo não se tornam justificativas morais para a acusação de um comportamento "desviante" ou fora da "normalidade" de um apostador. A teoria interacionista do desvio, ao focalizar, especialmente através de Howard S. Becker, o problema da acusação de desvio como forma de con- 
flito político, aponta para os mecanismos de poder envolvidos na negociação da realidade, desmitificando os modelos funcionalistas de patologia social (1996 e 1997). Nesse sentido, a acusação de desvio sempre tem uma dimensão moral que denuncia a crise de certos padrões ou convenções que dão ou davam sentido a um estilo de vida de uma sociedade, de um grupo ou segmento social específico. O cientista social procura ir além da denúncia moral para perceber as razões políticas que se sustentam. Por outro lado, Gilberto Velho (2004:61) aponta que a existência de uma ordem moral identificadora de determinada sociedade faz com que o desviante funcione como marco delimitador de fronteiras, permitindo que a sociedade se descubra, se perceba pelo que não é ou pelo que não quer ser.

Assim, com relação ao orçamento, existe um autocontrole maleável e que permite que jogadores se excedam com frequência ao longo de uma reunião do turfe. O controle total poderia impedir a fluidez e a diversão inerente ao jogo de tentar ganhar uma quantia maior. Como afirmou o jogador Cabeleira: "Tem horas que você sabe que vai ganhar, aí não se prende muito com isso, bota mais [dinheiro] pra aumentar o valor do prêmio". A existência de uma regra individual e subjetiva de montantes totais máximos a serem gastos com o jogo, por reunião, não inviabiliza que jogadores possam, vez ou outra, extrapolá-las sem lhes causar qualquer tipo de prejuízo moral perante seus pares. Exceder-se com valores acima de mil reais é perfeitamente aceito, legítimo e corriqueiro.

Além da questão orçamentária, a "categoria acusatória” de viciado ocorre também a partir dos limites de tempo relacionados à frequência com que um jogador permanece numa casa de apostas. A quantidade de horas presente nos dias de reunião pode ser fundamental para que um jogador acuse o outro de viciado. Como afirmou o jogador João e reforçado por Ivan, existiriam dias em que mais "viciados" estariam presentes do que em outros.

João: Tem cara não consegue não jogar um diazinho só. Tem gente aqui que vem sem dinheiro nenhum e é capaz de voltar pra casa a pé, mas se conseguir um troco vai gastar no cavalo. Coisa de viciado.

Ivan: Sábados e Domingos não. Esses dias só tem foguete correndo e quem vem ver [e jogar] não é viciado não. Agora segunda e sexta...

João: Segunda e sexta é dia de viciado. 
Deste modo, a frequência em determinados dias seria uma representação de apostadores que não conseguem ficar um dia sem jogar, permanecendo dias nas casas de jogos sem uma autoimposição de limites temporais. Quanto a isto, esta questão novamente remete a um autocontrole, regulado pelos próprios jogadores. Embora muitos dos que classifiquem estes dias como "dias com maior quantidade de viciados”, esta regra é também maleável, pois muitos são os que frequentam estes espaços em um número máximo de reuniões possíveis ao longo de toda semana.

Além dos limites orçamentários e temporais, um terceiro ponto está na forma como o jogo é empregado por parte dos apostadores. Trata-lo como um fim em si mesmo, isto é, a aposta pela aposta, sem reconhecer as técnicas, os saberes e a etiqueta envolvida no turfe é um dos argumentos utilizados para reforçar o estigma do jogador visceral. Como afirmou o jogador Paulinho: "Jogador de corrida de cavalos que aposta por necessidade, perde por obrigação”.

$\mathrm{O}$ aspecto lúdico surge na defesa do turfe quando visto como uma prática potencialmente perigosa, e, em geral, inserida no universo das responsabilidades sociais com a família e com o trabalho e de uma diversão simples e corriqueira. Em sua defesa (assim como em defesa do próprio jogo), o jogador Matias afirmou: "Eu não deixo de pagar as contas lá de casa, pago a faculdade de da minha filha. Esse dinheiro aqui é pra eu me divertir. Não tem nada a ver uma coisa com a outra”. Os gastos financeiros e temporais no jogo são, assim, muitas vezes, considerados como partes inerentes ao lazer do jogador. Um lazer no qual a família não toma parte e que, caso seja devidamente provida pelo jogador, não haveria motivos para questionamentos, já que há a existência da crença por muitos dos presentes na obrigatoriedade do papel do homem como o provedor das necessidades materiais familiares. Assim, segundo a lógica dos jogadores, se o homem provém para sua família, não haveria motivos de suspeita sobre seus gastos com a bebida e com o jogo.

Por outro lado, a categoria acusatória de viciado é atribuída aos que transformam as apostas nas corridas num fim em si mesmo, assim como a de drogado (Velho, 2004:64) explica, de imediato, a problemática da patologia individual. O viciado seria, por definição médica, um doente. A partir daí, constrói-se todo um discurso sobre anormalidade da prática de apostas e sobre as consequências nefastas para o indivíduo e para a sociedade. O viciado é questionado diretamente acerca de sua moral. $\mathrm{O}$ apostador que estabelece a aposta pela aposta se 
apresenta como um jogador que não age dentro da "normalidade" existente nas regras, negligenciando todo um escopo de saberes e condutas inerentes a esta atividade. Assim, a acusação de "viciado", para além de uma conduta autodestrutiva, reflete no status do jogador perante o grupo. Os que entendem e sabem jogar seriam aqueles capazes de flertar constantemente com os "perigos" inerentes ao jogo, sem que, com isto, seu caráter seja desvirtuado, pois eles seriam capazes de manter seu controle dentro dos limites aceitáveis, possibilitando a continuidade das apostas, mesmo que eventualmente possa haver uma ruptura nas regras criadas por eles. Assim, nas casas de jogo é possível se descontrolar, perder fortunas e frequentar diariamente as corridas sem que seja acusado de viciado. Uma tipificação moralizante de jogador “viciado” é estabelecida, mas não é atribuída especificamente a nenhum dos jogadores da casa, pois todos ali se consideram jogadores legítimos, de acordo com suas próprias regras.

\section{O anonimato no jogo dos doze passos}

Para os jogadores das casas de aposta, a noção do "vício" se estabelece como uma categoria acusatória de não ser dotado da capacidade e forma ideal de jogador. Entretanto, em nenhum momento ela se torna auto-atribuída. Como afirmei anteriormente, o limite do jogo se estabelece no penúltimo jogo, ou na penúltima vez jogada para que se possa manter a série de jogos constante (cf. Deleuze, 2008). Assim, como se constituiria a noção do "vício" quando esse limiar é ultrapassado e o último jogo tenha sido feito? Em certa medida, o que ocorre quando um jogador se reconhece como um viciado? Dificilmente, devido à forma com que esta categoria é construída nas casas de apostas, se poderia encontrar viciados nestes termos frequentando casas de jogo. Pois, segundo essa lógica, não existem viciados no jogo, somente fora dele.

Desta maneira, para discutir esta questão com maior profundidade, foi necessário pensar esta noção a partir de outros espaços que não contemplassem o jogo diretamente, mas que pudessem, em certa medida, trazer contribuições em contraste com a visão estabelecida nas casas de apostas. Foi a partir de contatos pessoais que tive acesso a um jogador anônimo ${ }^{8}$, que muito gentilmente me convidou para participar da reunião de comemoração de seus nove meses de abstinência de jogo em um dos encontros abertos do grupo dos Jogadores Anônimos (J.A.), do bairro do Flamengo?.

A forma como o J.A. realiza seus encontros se dá a partir de uma reelaboração 
dos encontros dos grupos Alcoólicos Anônimos (A.A.), o primeiro tipo de grupo a estabelecer os moldes e regras consolidadas de atuação com um modelo de autoajuda, ou ajuda mútua. Através da correlação direta entre a atividade de jogo e da bebida, a reconfiguração dos efeitos, danos, causas e distúrbios do consumo de álcool foram facilmente reenquadrados para os jogos de apostas. Para tornar-se membro de um J.A. basta que se aceite ficar sem jogar por 24 horas. Nenhuma verificação é feita, somente o testemunho do indivíduo é levado em conta. Pode-se entrar e sair do grupo, trocar e retornar ao grupo, tudo isso à vontade.

Para estes grupos, o vício no jogo é considerado uma doença incurável. Logo, o membro do J.A. será sempre um jogador, mas um jogador que não joga. Assim, nenhuma ruptura se produz entre os membros mais velhos e os recém-aderidos. Não existe um lado doente e, do outro lado, aquele que cura. Os traços tradicionais de funcionamento baseiam-se em ouvir outro membro contar histórias de seu passado de jogador. Chama-se isso de "compartilhar" e a estrutura dos encontros se dá também a partir da equivalência com a inclusão dos " 12 passos de recuperação ${ }^{10}$, do anonimato e da ajuda mútua entre membros do grupo a partir de encontros regulares.

No J.A., a categoria do vício no jogo é reconfigurada a partir do patológico ou do desviante (Becker, 2008). Os defeitos de caráter e a propensão à compulsão seriam traços imanentes e naturais de certas pessoas. Em tais grupos, é inserida a ideia da existência de um comportamento normativo a ser seguido pelo jogador anônimo e que ele seria incapaz de gerar por si só uma transformação positiva nesta direção. E assim é tratado como traço que exige cuidados constantes. Segundo anunciado nos panfletos do J.A:

Nossa experiência tem demonstrado que, quando chegamos a Jogadores Anônimos, já adquirimos uma série de defeitos de caráter. Era virtualmente impossível jogar compulsivamente sem mentir, roubar, esquivar-se da realidade e recorrendo a um mundo de fantasias, algumas vezes se beneficiando de todos os três. Descobrimos que parar de jogar não nos liberta desses defeitos automaticamente ${ }^{11}$.

A moralidade aqui não está no vício e nem no indivíduo, ela é transferida para um plano transcendental. Como apontou a antropóloga Rebecca Cassidy (2002), o jogo de apostas é enunciado como uma prática que, ao levar ao vício, retira a intencionalidade da ação do jogador compulsivo: 
O jogo passou a ser descrito como um vício. Este vocabulário é a versão moderna do que é encontrado na figura do "jogador compulsivo" e a linguagem do 'Jogadores Anônimos' lança o jogador como sujeito a forças exteriores, ao invés de um agente da ação intencional (Cassidy, 2002:71).

Apesar de o viciado possuir um comportamento socialmente desviante e compulsivo, estas características se sobreporiam às ações dos jogadores que seriam incapazes de produzir uma ação independente. Da mesma maneira, a "cura”, ou o tratamento, se dá através da transferência da ação para o plano sagrado, para um "poder superior" presente em 4 dos doze passos. Esta troca de responsabilidades estabelecidas nas dicotomias entre norma e desvio, e a "sagrado e profano" (Durkheim, 1996) auxiliam na diminuição da relação de culpa do jogador, haja visto que ele não seria mais o detentor do controle de suas ações. Esta relação, muitas vezes, advém de duas linhas centrais: a primeira no plano econômico e a segunda no plano das externalidades causadas a outras pessoas (principalmente aos parentes e amigos mais próximos). Quanto a isso, o autor Jacques Godbout (1999) argumenta que a estes grupos de ajuda mútua estabelecem sistemas de dádivas: tanto na sua filosofia quanto no seu modo de funcionamento:

Tal reconhecimento [de sua incapacidade frente ao problema] significa que a pessoa rompe com o narcisismo do indivíduo moderno, narcisismo que provoca nele uma confiança ilimitada de sua capacidade pessoal de ser "independente e autônomo" e um temor também ilimitado de ser absorvido pelo outro (Godbout, 1999:85-6)

Assim, os gastos que tiveram aumentos exponenciais no jogo, anteriores à abstinência, seriam um dos focos da modificação comportamental almejada pelo grupo. A aceitação da perda é apresentada como necessária para que o ex-jogador evite tentar reaver o dinheiro perdido por intermédio da continuação no jogo, pois, mesmo que o ganho venha fácil, ele vai fácil, e acaba-se por perder cada vez mais. É possível exemplificar este ponto a partir da narrativa da trajetória do jogador anônimo que me levou a estes grupos. Seu percurso até chegar a se considerar "jogador anônimo" teve início através de uma profissionalização no jogo. Desde cedo, afirmava ser bom com números e jogos, tanto que, eventualmente, se tornou croupier $^{12}$ de pôquer, chegando a trabalhar em torneios importantes no país. A partir de contatos no jogo, foi convidado para administrar uma mesa de pôquer no bairro de Copacabana em um cassino clandes- 
tino cujo dono era um renomado banqueiro do "jogo do bicho" (Soares, 1993; Damatta \& Soárez, 1999; Magalhães, 2005 \& Labronici, 2012). A partir dessa entrada nos cassinos, tomou gosto pelas máquinas caça-níqueis:

Cara, cada aperto de botão era 80 Reais. Eu falava pra mim mesmo que não ia jogar muito e não levava dinheiro, mas a casa me dava crédito. Já quebrei meu cartão de crédito pra evitar sacar, mas não adiantava. Levava 300 Reais e gastava $5 \mathrm{mil}$. Já cheguei a ficar 50 horas dentro do cassino sem parar. Dá pra ter uma ideia de quanta grana eu já perdi no jogo.

Da mesma forma que para um jogador de turfe nas casas de apostas o vício no jogo encontra-se nos gastos descontrolados, para o J.A a questão encontra-se inserida na chave da compulsividade ou de uma patologia, uma doença. No momento em que a doença é encontrada, se exclui o doente (Foucault, 1997). Um anônimo considera-se incapaz de produzir limites, e o melhor curso de ação a ser tomado seria a abstinência total e irrestrita. A busca pelo controle de si é estabelecida de modo a não se fazer a primeira aposta, para não restabelecer novamente a série de jogos. Apesar de ser apresentado como um fim em si mesmo, o jogo não é apresentado como um mal em si. A união das potencialidades viciantes do jogo com as falhas no caráter do jogador seriam as bases e o foco da patologia.

A relação de culpa de um jogador anônimo é também apresentada discursivamente a partir dos efeitos externos da ação de apostar causados nas pessoas de convívio mais próximo, principalmente no âmbito familiar. A partir de uma ingovernabilidade da própria vida, consequências indesejadas como "sofrimento e dor", causados a familiares, demandariam "reparações", aspecto presente em três dos doze passos de recuperação. A motivação econômica neste caso também está presente, pois, além dos constantes gastos, somam-se a eles o acúmulo de dívidas e empréstimos frequentes, algumas vezes recorridos a grupos de agiotagem.

No dia da reunião dos nove meses de abstinência do jogador anônimo, foi possível observar este outro lado. Por se tratar de uma reunião comemorativa, parentes e amigos próximos do jogador anônimo se fizeram presentes. Muitos deles, como a mãe, o padrasto e a avó, utilizaram de seu espaço de fala para relembrar momentos da vida do jogador antes e depois de sua entrada no jogo, com discursos carregados de emoção por parte da família, corroborando a ideia da presença de um sofrimento externo causado pela ação do jogador e tencio- 
nando uma relação entre o controle individual e social das emoções (Rezende \& Coelho, 2010), refratando uma abordagem de natureza não exclusivamente individual. Aos olhos do J.A. a ação do jogador, seria assim, individual, incontrolável, economicamente desgastante e com efeitos que ultrapassariam os limites do próprio jogo.

Embora marcadores socioeconômicos possam ser estabelecidos comparativamente entre as reuniões do turfe e as do J.A., indivíduos oriundos de classes baixas e altas frequentam tanto as casas de apostas como o J.A., com uma pequena variação que, a meu ver, não é muito significativa. Apesar disso, a origem social pode interferir na sociabilidade entre os integrantes destes espaços. Assim, ambas contêm um perfil extremamente plural e que é muitas vezes refletido nos valores gastos no jogo. Apesar disso, é possível afirmar que as reuniões do turfe se constituem como espaços de construção de uma masculinidade (Guedes, 1997), pois o perfil dos jogadores é predominantemente masculino, onde ocorre a segregação espacial das mulheres como uma necessária fonte de criação e legitimação de uma identidade masculina, o que se distingue das reuniões do J.A. que, até onde pode ser constatado, tais marcadores de criação e legitimação de masculinidade não estão presentes. Além disso, “jogadoras anônimas”, na maioria das vezes são oriundas de outros jogos, como: caça-níqueis, bingos, cartas, etc., o que pode ser considerado um reflexo destes espaços masculinizantes do turfe. Existe um ditado para os J.A. que é: "As reuniões produzem”, mas produzem o exato oposto do que as reuniões do turfe. Enquanto no turfe as reuniões produzem jogo, as reuniões do J.A. produzem o "não jogo", ou a "recuperação" da compulsividade a partir de sua frequência na busca por melhorias. Essa forma de enxergar determinadas práticas como uma doença incurável e inata na natureza individual traz a associação com diversos outros possíveis vícios, associação presente em quatro dos 12 passos de recuperação. Assim, não é incomum observar jogadores anônimos que frequentam outros grupos como os Alcoólicos Anônimos (A.A.), Mulheres que Amam Demais Anônimas (M.A.D.A.), Neuróticos Anônimos (N.A.) Narcóticos Anônimos (N.A.), entre outros.

A "recuperação" atrelada à presença nas reuniões pode se inserir como uma concorrência na busca para retirar o jogador do convívio dos estabelecimentos de jogos, como as casas de aposta do turfe. O apadrinhamento por parte de outro jogador anônimo estabelece um fortalecimento de laços nestes espaços na 
busca pela difusão da "mensagem" ( $12^{\circ}$ passo de recuperação). Com relação ao apadrinhamento nos grupos de ajuda mútua, Jacques Godbout (1999) aponta:

Assim, os Alcoólicos Anônimos (AA) [do mesmo modo que os Jogadores Anônimos (J.A.)] são regidos pelo princípio de reciprocidade, mas são abertos a alteridade. Tão logo "curados", seus membros devem transmitir a outros aquilo que receberam, ajudar um alcoólico [jogador], em suma integrar-se numa cadeia de dádiva, o que se opõe ao caráter binário ou simétrico que usualmente define a palavra reciprocidade (Godbout, 1999:83).

Com isso, entendo que a noção de pessoa apresentada pelos J.A., em certos aspectos, vai de encontro ao sectário, individual e consciente, conforme assinalado por Mauss ([1938] 2003:395) ${ }^{13}$. O J.A., assim como no pensamento cristão, fez do conceito de pessoa moral, consciente do bem e do mal, uma pessoa metafísica, incompleta e atrelada à regência da figura do sagrado. A forma fundamental do pensamento e da ação é reconfigurado a partir da culpa, na qual o jogador anônimo compulsivo abre mão de suas vontades e desejos na busca de um tratamento para seus males.

\section{Conclusão}

Nos jogos de apostas, o vício e o viciado são categorias acusatórias (Velho, 2004) e estigmatizantes (Goffman, 1988) que permeiam a realidade dentro e fora das casas de jogo. Os perigos atrelados a tais práticas trazem no seu contato rupturas com uma "normalidade" e com os controles de si (Foucault, 1979) vigentes por um aspecto moralizante que incide diretamente no caráter do jogador. O foco de alguns dos principais aspectos tratados na obra Estabelecidos e Outsiders - de Elias e Scotson (2000) -, contribuem para esclarecer as relações de poder entre grupos socialmente distintos. Um moralismo dos estabelecidos - que se posicionam como defensores de uma ética dos "bons costumes” através da abstinência dos J.A. - e a construção de uma imagem negativa referente aos outsiders, com os apostadores de turfe. A abordagem inclui a ideia de que é preciso ir além das estruturas de personalidades dos indivíduos para se chegar às razões geradoras de preconceitos e estigmatizações sociais, revelando, assim, as práticas que servem aos interesses de um grupo em oposição ao outro. E, no caso dos jogos, ambos os grupos disputam a moral vigente da atividade.

A "hierarquia sócio-moral" (Geertz, [1973] 2008:200), distinguindo jogos de 
status e jogos de "dinheiro", é reforçada em ambos os espaços e é, muitas vezes, evidenciada pelos valores ganhos e gastos de jogadores e anônimos. O fato de se introduzir o papel do dinheiro na relação com as apostas é considerado um ponto fundamental. A função comparativa da categoria de "vício" entre estes dois espaços de reunião é oriunda de um discurso moral e que, por sua vez, é um reflexo material entre as quantias monetárias efetuadas com esta atividade, rotineiramente. Em ambos os casos, os valores servem de indicador dos limites em que a atividade ultrapassa o "limiar" (Deleuze, 2008) e se torna um "problema” a ser evitado. Não sendo fixos em si, mas operantes em uma lógica de gastos compulsivos e destrutivos em vários aspectos da vida, principalmente como a relação com trabalho e a família. Apesar desse ponto de similaridade, cada uma das reuniões, como foi demonstrado, lida com essa questão a sua própria maneira.

O jogo, como definido por Roger Caillois (2001), uma atividade voluntária, separado da realidade cotidiana no espaço tempo incerto e não produtivo, seria dotado de características de disputa, sorte, excitação e, a união com as apostas contribuiriam para a passagem do lúdico ao perigoso. O gradiente de emoções (Resende \& Coelho, 2010) acionados durante a prática de apostas seria outro ponto de convergência. A busca por reaver gastos outrora perdidos se consolida como o foco de ruptura. Os excessos são assim apreciados ou como uma concepção normal "coisas do jogo" ou como prática tal que deve ser evitada a qualquer custo.

Por mais que o seu peso moral seja extremamente variado e complexo, como tentei demonstrar ao longo do texto, evita-se o vício a partir da imposição de limites e controles na ação dos indivíduos. Enquanto que, por um lado, o vício nas casas de aposta se apresenta como uma imperícia, no J.A. ele se apresenta na relação da compulsividade patológica e incurável. De um lado, as liberdades individuais possibilitam que o jogador imponha sobre si controles maleáveis e flexíveis. Do outro, a abstinência é o único remédio. Apesar desta categoria estar presente nestes dois espaços, ficou evidente como ela é construída de maneira distinta, de uma ação consciente através da imposição de limites a traços de uma natureza humana imutável e patológica. Assim, como aludido ao longo do texto, a moralidade imputada nos jogos de apostas se apresenta como um campo (Bourdieu, 2004), um lugar de luta entre os agentes que o integram e que buscam manter ou alcançar determinadas posições. Essas posições são 
obtidas pela disputa de capitais específicos, valorizados de acordo com as características de cada campo, e que, no caso do jogo, se encontra na própria definição da categoria de "vício".

Recebido: 06/06/2017

Aprovado: 13/03/2018

Rômulo Bulgarelli Labronici é doutor e mestre pelo Programa de Pós- Graduação em Antropologia da UFF. Coordenou o mestrado em Direito da regulação da FGV/RJ. É pesquisador do INCT-InEAC/UFF e realiza pós-doutoramento no PPGA-UFF (Bolsista FAPERJ). Trabalha com questões etnográficas voltadas para antropologia econômica, urbana e relações entre homens e animais. Publicou o livro: Na pata do cavalo: um estudo etnográfico com apostadores do turfe em agências credenciadas do Jockey Club Brasileiro (2017). Contato: romulolabronici@gmail.com

\section{Notas}

1. Os Agentes Credenciados são também denominados simplesmente por: "agentes", "lojas", "casas", "casa de aposta", "casa de jogo" ou simplesmente de "credenciados". Tais estabelecimentos foram viabilizados a partir do Decreto N $^{\circ}$ 96.993, de 17 de outubro de 1988, que regula, dentre outras questões referentes ao turfe, a sua prática das apostas e estabelece a Comissão Coordenadora da Criação do Cavalo Nacional CCCCN, diretamente subordinada ao Ministro de Estado da Agricultura.

2. No turfe, o conceito de "barbada" é o mais enigmático, pois a sua chave de enunciação está em uma suposta garantia de vitória, cavalo imperdível ou aposta infalível. Que, ao contrário do que ocorre com um palpite convencional, a barbada possui um grau especulativo menor e com um traço marcante de previsibilidade do resultado final.

3. O termo "Toddynho" é derivado de uma marca de bebida achocolatada associado ao consumo infantil. Mencionar que o outro irá tomarToddynho é tido como uma pro- 
vocação equivalente à afirmação de que não há maturidade o suficiente para o jogo.

4. A autora Kate Fox (cf. 2005:7-8) trata do viciado [Addict] quanto uma tipificação de apostador turfista. Entretanto, aqui pretendo discutir com uma visão distinta para esta questão, atribuindo ao "viciado" quanto uma categoria nativa de acusação aos que por ventura possam romper com as regras e normas estabelecidas pelo grupo de jogadores.

5. O "estudo" do programa é o ato de ler e analisar classificatoriamente todos os dados apresentados nos páreos do programa. Em geral, não é realizado com apenas um páreo, mas a partir da totalidade dos páreos de uma reunião. Assim, os turfistas portarão os respectivos programas do dia e que, muitas vezes, servirão também como uma espécie de "bloco de notas" onde os jogadores escreverão números, realizarão tabelas e anotarão seus palpites antes de efetivamente realizar uma aposta diretamente nos guichês de apostas. $\mathrm{O}$ estudo consiste assim em um ato individual particular de cada jogador momentos (horas ou até mesmo dias) que antecederão a reunião.

6. As "mesas de ronda" ou "ronda da madrugada" são mesas de jogo com baralho. Reconhecidas como o jogo de apostas mais rápido que existe. Consiste em apostar em duas cartas retiradas aleatoriamente do baralho nas quais dois jogadores irão escolher entre elas. A medida que novas cartas vão sendo retiradas a primeira que coincidir com a de um dos dois jogadores ganha. Os jogos de Ronda, são em geral rotulados como foco de diversão da malandragem onde a honestidade está fora do jogo e chance de ser enganado é a única certeza.

7. Os dez mandamentos do apostador em Cavalos de Corrida foram criados por Phil Bull, Criador de cavalos de corrida e também um dos maiores ganhadores de jogo de aposta em cavalos de corrida da Inglaterra, em todos os tempos. De 1943 a 1975, Bill adquiriu uma fortuna acumulada em aproximadamente U\$ 8 milhões e teve a sua conta encerrada em várias casas londrinas sob o argumento de que "acertava demais". Os dez mandamentos do apostador se tornaram uma espécie de "Bíblia" para todos os "punters" [apostadores] e bookmakers londrinos. Assim sendo, os dez mandamentos do apostador são: $1^{\circ}$ : Vá as corridas para ver os cavalos e não as pessoas. $2^{\circ}$ : Veja o cavalo no padoque. $3^{\circ}$ : Confirme no cânter o que os cavalos já "informaram" no padoque. $4^{\circ}$ : Jóqueis e treinadores são sempre os piores informantes. $5^{\circ}$ : Tente entender os cavalos e o turfe de modo geral, antes de arriscar o seu dinheiro. $6^{\circ}$ : Só aposte alto quando o rateio é maior do que devia ser. $7^{\circ}$ :Tenha presente que, a longo prazo, apostando alto em todas as reuniões, você é um homem morto. $8^{\circ}$ : O condicionamento físico dos cavalos, a habilidade dos jóqueis, o número da baliza na largada, o estado da pista, a distância do páreo e os 
méritos de cada animal indicam sempre quem ganha e quem perde. $9^{\circ}$ : Nunca acredite em falácias tais como: a sorte é determinante no turfe, ou que não se deve jogar em favorito. $10^{\circ}$ : Nunca se permita “correr atrás” dos eventuais prejuízos, nem se apaixonar por um determinado cavalo.

8. Neste trecho, os nomes dos interlocutores serão tratados apenas como "jogador(es) anônimo(s)", em respeito com a forma como tais atores lidam com esta questão mantendo coerência com o anonimato estabelecido por estes grupos.

9. No Rio de Janeiro existem diversos grupos de J.A. que se encontram em média duas vezes por semana em reuniões fechadas e abertas. Separados por algumas regiões: Acre, Arpoador, Barra da Tijuca, Campo Grande, Copacabana, Estácio, Flamengo, Nilópolis, Niterói, Pilares, Tijuca e um grupo com reuniões On-line. Além disso, o modelo deste grupo de autoajuda possui um grupo denominado JOG-ANON voltado ao auxílio dos familiares dos membros destes grupos.

10. Os doze passos de recuperação do J.A: $1^{\circ}$ : Admitimos que éramos impotentes perante o jogo e que nossas vidas haviam se tornado ingovernáveis. $2^{\circ}$ : Passamos a acreditar que um Poder Superior a nós poderia trazer-nos de volta a um modo normal de pensar e viver. $3^{\circ}$ : Tomamos a decisão de entregar nossa vontade e nossas vidas aos cuidados deste Poder de nosso entendimento. $4^{\circ}$ : Fizemos um minucioso e destemido inventário moral financeiro de nós mesmos. $5^{\circ}$ : Admitimos a nós mesmos e a outro ser humano a natureza exata de nossas falhas. $6^{\circ}$ : Dispusemo-nos inteiramente a remover estes defeitos de caráter. $7^{\circ}$ : Humildemente pedimos a Deus de nosso entendimento que removesse as nossas imperfeições. $8^{\circ}$ : Fizemos uma lista de todas as pessoas que prejudicamos e tornamo-nos dispostos a fazer a recuperação a todos pelo mal causado. $9^{\circ}$ : Reparamos diretamente os danos causados a essas pessoas, sempre que a reparação não implicasse prejuízos para elas ou outros. $10^{\circ}$ : Continuamos nosso inventário pessoal e prontamente admitimos nossos erros. $11^{\circ}$ : Procuramos, mediante a oração e a meditação, melhorar nosso contato consciente com Deus de nosso entendimento, pedindo somente o conhecimento de sua vontade perante nós e a capacidade de realiza-la. $12^{\circ}$ : Tendo feito um esforço para praticar estes princípios em todas as ocasiões, procuramos levar esta mensagem a outros jogadores compulsivos.

11. Jogadores Anônimos, em direção... aos 90 dias (panfleto adquirido nas reuniões do JA).

12. Um croupier é alguém nomeado em uma mesa de jogo para ajudar na sua condução, especialmente na distribuição de apostas e pagamentos. Normalmente são empregados apontados pelos estabelecimentos de jogo. 
13. A categoria do Eu, classifica-se e identifica-se como o conhecimento de si, com a consciência psicológica. Esta forma do Eu como categoria se desenvolveu a partir de um longo percurso do direito e da moral, como afirma Mauss ([1938] 2003): "De uma simples mascarada à máscara; de um personagem a uma pessoa, a um nome, a um indivíduo; deste a um ser com valor metafísico e moral; de uma consciência moral a um ser sagrado; deste a uma forma fundamental do pensamento e da ação; foi assim que o percurso se realizou” ([1938] 2003:397).

\section{Referências bibliográficas}

BURNHAM, John C. 1993. Bad Habits, drinking, smoking, taking drugs, gambling, sexual misbehavior, and swearing in American History. New York: New York University Press.

BARCELOS, Sérgio. 2002. Cavalos de corrida: uma alegria eterna. Rio de janeiro: Topbooks.

BECKER, Howard S. 2008. Outsiders, estudos de sociologia do desvio. Rio de Janeiro: Zahar.

BOURDIEU, Pierre. 2004. Os usos sociais da ciência: por uma sociologia clínica do campo científico. São Paulo: UNESP. 86 p.

CAILLOIS, Roger. [1958] 2001. Man, play and games. Urbana and Chicago: University of Illinois Press, [Le jeux et les hommes].

CASSIDY, Rebecca. 2002. The Sport of the kings. Kinship, class and thoroughbred breeding in Newmarket. United Kingdom: Ed. Cambridge University Press.

CARVALHO, Ney O. R. (editor). 1998a. O Turfe no estado do Rio de Janeiro. Rio de Janeiro: Imprinta Gráfica e Editora. 1998b. Jockey Club Brasileiro 130 anos - Rio de Janeiro, um século e meio de Turfe. Rio de Janeiro: Imprinta Gráfica e Editora.

DAMATTA, Roberto. 1979. Carnavais, malandros e heróis: para uma sociologia do dilema brasileiro. Rio de Janeiro: Record.

DAMATTA, Roberto; SOÁREZ, Elena. 1999. Um estudo antropológico do jogo do bicho. Rio de Janeiro: Rocco.

DELEUZE, Gilles \& FÉLIX, Guattari. [1997] 2008. Mil platôs - capitalismo e esquizofrenia. $4^{\mathrm{a}}$ reimpressão. São Paulo: Editora 34. vol 5.

DOUGLAS, Mary. 1976. Pureza e Perigo. Rio Janeiro: Editora Perspectiva.

ELIAS, Norbert; SCOTSON, John L. [1965] 2000. Os estabelecidos e os outsiders. Rio de Janeiro: Ed. Zahar.

FOX, Kate. 2009. The Racing Tribe, portrait of a British Subculture. New Brunswick 
and London: Ed. Transaction Publishers.

FOUCAULT, Michel. 1997. A história da loucura na idade clássica. São Paulo: Ed. Perspectiva.

2000. Vigiar e punir. Tradução Raquel Ramalhete. 23. ed. Rio de Janeiro: Vozes.

GEERTZ, Clifford. [1973] 2008. A Interpretação das culturas, Rio de Janeiro: Guanabara Koogan.

GODBOUT, JacquesT. \& CAILLÉ, Alain. 1999. O espírito da dádiva. Rio de Janeiro: Fundação Getúlio Vargas.

GOFFMAN, Erving. 1988. Estigma: Notas Sobre a Manipulação da Identidade Deteriorada. 4 ed. Rio de Janeiro: Livros Técnicos e Científicos.

GUEDES, Simoni Lahud. 1997. Jogo de corpo - um estudo da construção social de trabalhadores. Niterói: EDUFF.

LABRONICI, Rômulo. 2012. Para todos, vale o escrito: uma etnografia do jogo do bicho. Dissertação, PPGA/UFF.

MAGALHÃES, Felipe Santos 2005. Ganhou Leva... Do Vale Impresso ao Vale ao escrito. Uma história social do jogo do bicho no Rio de Janeiro (1890-1960). Tese de doutorado apresentada ao PPGHS - UFRJ. Rio de Janeiro.

MAUSS, Marcel. 2003. Sociologia e Antropologia. São Paulo: CosacNaify, [1950].

MARCUS, George E. 1995. "Ethnography in theWorld System:The emergence of multi-sited Ethnography”. Annual Review of Anthropology, vol. 24:95-117.

MELO, Victor Andrade de. 2001. Cidade esportiva: primórdios do esporte no Rio de Janeiro. Rio de Janeiro: Ed. Relume Dumará.

MISSE, Michel. 1999. Malandros, Marginais eVagabundos \& Acumulação Social daViolência no Rio de Janeiro. Tese de doutorado em Sociologia, IUPERJ. Rio de Janeiro.

REZENDE, Cláudia Barcellos \& COELHO, Maria Claudia. 2010. Antropologia das emoções. Série Sociedade \& Cultura. Rio de Janeiro: Ed. FGV.

SIMMEL, George. 1983. Sociabilidade: um estudo de sociologia pura ou formal. MORAES FILHO, E. (Org.). Sociologia. São Paulo: Ática, [1908]. p. 165-181.

SOARES, Simone Simões Ferreira. 1993. Jogo do bicho, um fato social brasileiro. Rio de Janeiro: Bertrand Brasil.

VELHO, Gilberto. 2004. Individualismo e Cultura, notas para uma antropologia da sociedade contemporânea. Rio de Janeiro: Zahar. 
Resumo: Apesar da popularidade da prática de apostas no turfe, esta atividade aponta para uma fronteira moral inserida em suas estruturas. Durante a realização das corridas de cavalos, um sinal de alerta é constantemente acionado para com os limites que cada indivíduo possui com as apostas. Aqui, busca-se compreender como a categoria "vício" [no jogo] é imputada de valores estigmatizantes, acusatórios, em dois espaços distintos. $\mathrm{O}$ primeiro organizado para a realização de apostas em comparação com outros espaços onde se prega a abstinência desta atividade. Refiro-me aqui às "casas de jogo" e dos encontros regulares de grupos de autoajuda, denominados de Jogadores Anônimos (J.A.). A comparação busca compreender as disputas sobre a moral do jogo como um "campo" nos moldes de Bourdieu (2004) a partir da construção de narrativas que vão apresentar o jogo como uma atividade mais ou menos perigosa.

Palavras chave: Turfe; vício; jogo; apostas; estigma
Abstract: Despite the popularity of betting practice in the turf this activity points to a moral boundary that exists in its daily life. During horseracing an alert signal is constantly triggered to the limits that each individual has with the bets. Here, one tries to understand how the category "addiction" [in the game] is imputed of stigmatizing and accusatory values, in two different spaces. The first is organized for betting in comparison with other spaces where the abstinence of this activity is predicted. I refer here to "gambling houses" and regular meetings of self-help groups called Gamblers Anonymous. The comparison seeks to understand the disputes about the moral of the game as a "field" in the mold of Bourdieu (2004) from the construction of narratives that will present the game as a more or less dangerous activity.

Keywords: Turf; vice; game, gambling, stigma 